Family Profile No. 30, 2019

\title{
Older Adults' Living Arrangements and Citizenship Status
}

Author: Colette Allred

The number of foreign-born older adults (aged 65 and older) living in the United States has grown substantially over the past few decades, nearly doubling between 1990 and 2010 (Batalova, 2012). Many have migrated at older ages often to be with their adult children and grandchildren who are already living in the U.S. (Tienda, 2017). Noncitizens are foreign-born residents who do not possess U.S. citizenship, the majority of whom are in the country legally (Pew, 2019). In this Family Profile, we use the 2017 American Community Survey to examine older adults' living arrangements by gender, citizenship, and poverty status. Our sample includes men and women aged 65 and older who live in the U.S.

\section{Living Arrangements and Citizenship}

- Among citizens, the modal living arrangement category was residing with a spouse/partner only. This was more common for men (56\%) than for women (37\%).

- For noncitizens, men most often lived with a spouse/partner and others (37\%), whereas women most often lived with others (49\%).

Figure 1. Living Arrangements of Adults Aged 65 \& Older by Citizenship \& Gender

Men

Citizen Noncitizen

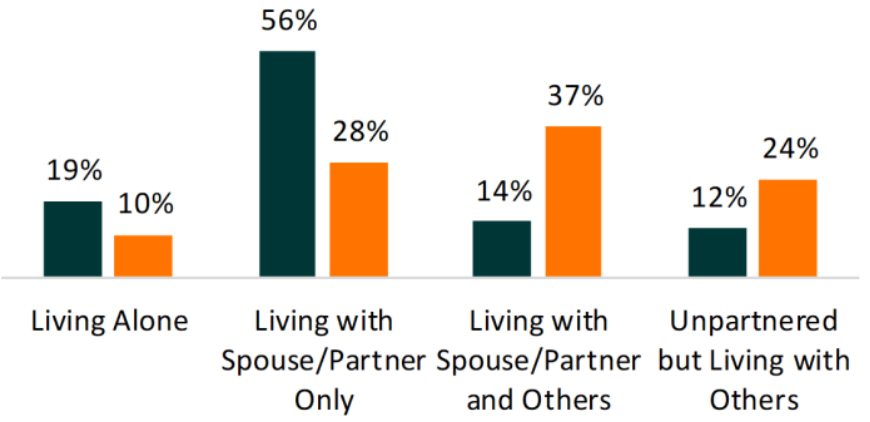

Women

- Citizen Noncitizen

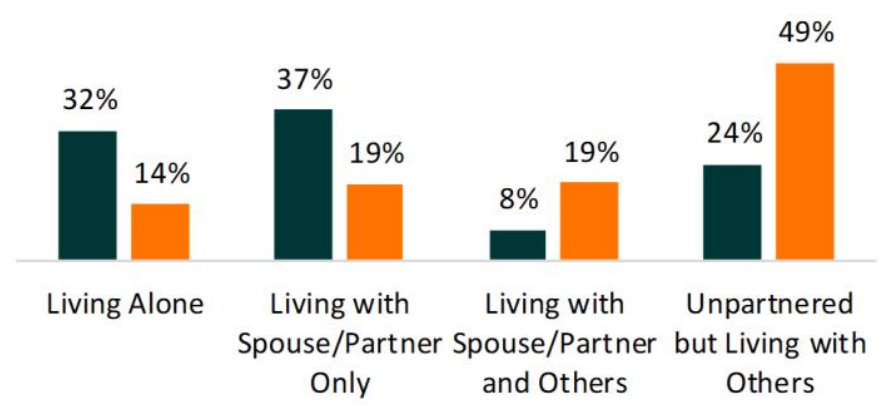

Source: NCFMR analyses of U.S. Census Bureau, 2017 American Community Survey, 1-yr est.

\section{Living Arrangements and Citizenship Below the Poverty Line}

- More noncitizens were below the poverty line, regardless of their living arrangements.

- Regardless of citizenship status or gender, those who lived alone were more often below the poverty line. This was more common for women ( $18 \%$ for citizens, $43 \%$ for noncitizens) than for men ( $15 \%$ for citizens, $38 \%$ for noncitizens).

Figure 2. Share of Adults Aged 65 \& Older Who Were Below the Poverty Line by Living Arrangement, Citizenship Status, \& Gender

Men

- Citizen $\quad$ Noncitizen
Women

Citizen Noncitizen
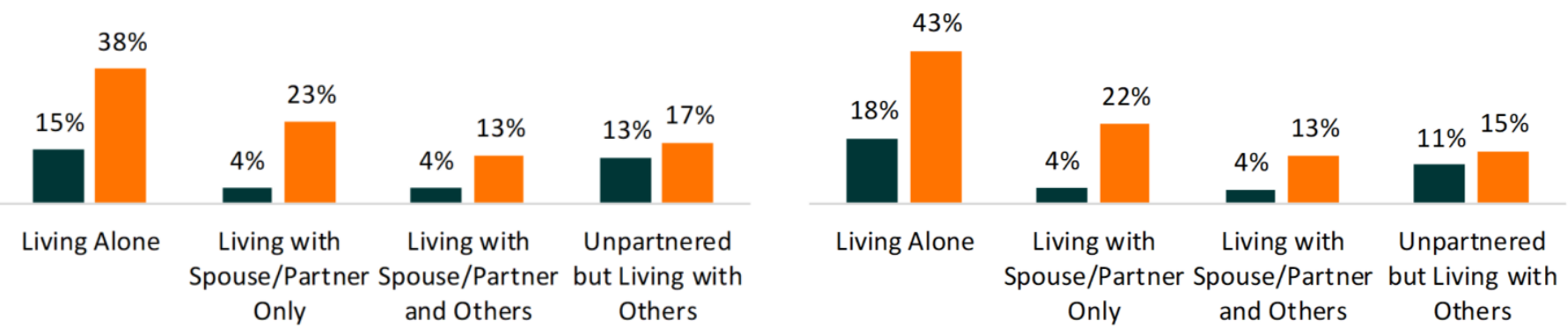

Source: NCFMR analyses of U.S. Census Bureau, 2017 American Community Survey, 1-yr est. 


\section{Noncitizen Older Adults, Migration Timing, and Living Arrangements}

- The highest share of older noncitizen women who migrated to the U.S. at age 50 or older were among those who were unpartnered but living with others (61\%). Among their male counterparts, less than half (46\%) had migrated at older ages.

- Over half of noncitizen men (52\%) and women (55\%) who were living with a spouse/partner and others migrated at age 50 or older.

- The smallest shares of older noncitizen men and women who migrated to the US at age 50 or older were among those who lived alone (24\% and $27 \%$, respectively).

Figure 3. Share of Noncitizens Aged 65 \& Older Who Migrated to the U.S. at Age 50 or Older

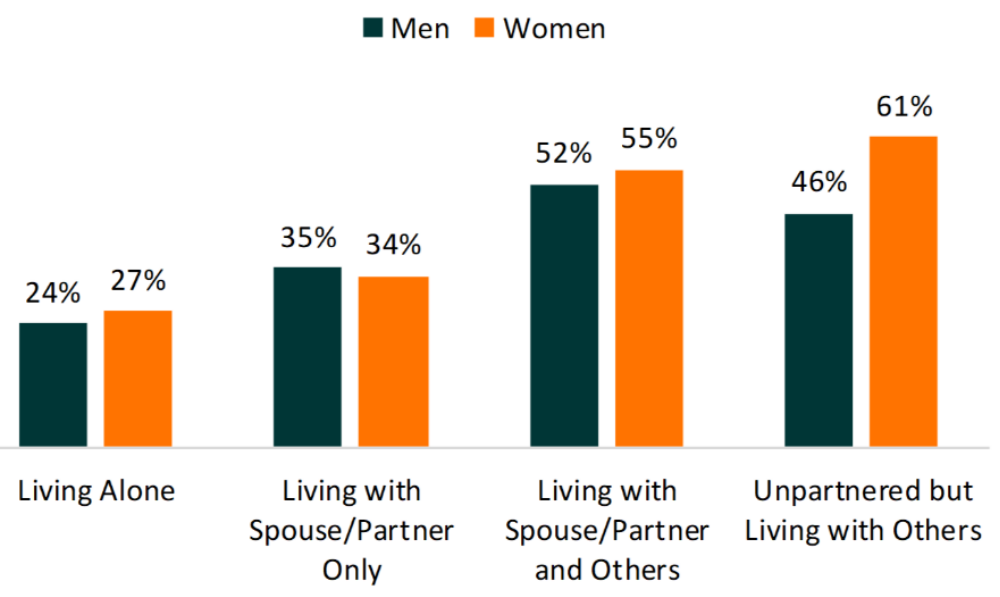

Source: NCFMR analyses of U.S. Census Bureau, 2017 American Community Survey, 1-yr est.

Note:

1. The citizen category includes foreign-born naturalized citizens, in addition to those born in the U.S.

2. The "others" in the categories of "Living with Spouse/Partner and Others" and "Unpartnered but Living with Others" might consist of the respondents' adult children, other family members, or non-relatives.

\section{Data Sources:}

Ruggles, S., Flood, S., Goeken, R., Grover, J., Meyer, E., Pacas, J., \& Sobek, M. IPUMS USA: Version 9.0 [2017 ACS]. Minneapolis, MN: IPUMS, 2019. https://doi.org/10.18128/D010.V9.0

\section{References:}

Batalova, J. (2012). Senior immigrants in the United States. Migration Information Source, May 30. http://www.migrationinformation.org/usfocus/display.cfm?ID=894.

Pew Research Center. (2019). Key findings about U.S. immigrants. https://www.pewresearch.org/fact-tank/2019/06/17/key-findings-aboutu-s-immigrants/

Tienda, M. (2017). Multiplying diversity: Family unification and the regional origins of late-age US immigrants. International Migration Review, 51(3): 727756.

\section{Suggested Citation:}

Allred, C. (2019). Older adults' living arrangements and citizenship status. Family Profiles, FP-19-30. Bowling Green, OH: National Center for Family \& Marriage Research. https://doi.org/10.25035/ncfmr/fp-19-30 